\title{
IGUALDAD EN REBAJA. REFLEXIONES CRÍTICAS EN TORNO A LA FILOSOFÍA POLÍTICA DE RONALD DWORKIN
}

EQUALITY ON DISCOUNT. CRITICAL REFLECTIONS ON THE POLITICAL PHILOSOPHY OF RONALD DWORKIN

Gustavo Arosemena *

Resumen: El artículo presenta una crítica a la filosofía política igualitaria de Ronald Dworkin a la luz de concepciones alternativas de la igualdad. Primero, a la luz de una igualdad política basada en el pensamiento de Thomas Hobbes. Luego, a la luz de una igualdad "mística" basada en la obra de autores como Elizabeth Anscombe y Bernard Williams. Se sostiene que estas dos concepciones alternativas de la igualdad son más fuertes que la presentada por Dworkin y que juntas dejan poca cabida para la especie de igualdad liberal preferida por este autor. Al final, el artículo presenta reflexiones acerca de la importancia de concederle a la ética un rol más fuerte que el avizorado por Dworkin en la fundamentación te teorías normativas. Dworkin busca crear una relación de reenvío y mutua acomodación entre ética y moral. En realidad, la ética tiene primacía y lo que debe buscarse no es acomodar estas dos ideas, sino derivar completamente la moral de la ética.

Palabras clave: Dworkin, igualdad, ética, moral, liberalismo

\footnotetext{
* Docente, Departamento de Derecho International y Europeo, Universidad de Maastricht (Países Bajos). gustavo.arsoemena@maastrichtuniversity.nl
} 
Abstract: The article presents a critique of the egalitarian political philosophy of Ronald Dworkin in light of two alternative conceptions of equality. First, in light of a political conception of equality based on the thoughts of Thomas Hobbes. Afterwards, in light of a "mystical" conception of equality based on the work of authors such as Elizabeth Anscombe and Bernard Williams. It is held that these conceptions of equality are stronger than the one presented by Dworkin and that together they leave little room for the liberal equality that Dworkin prefers. In the end, the article presents reflections on the importance of granting ethics a stronger role in grounding normative theories than the one given by Dworkin. Dworkin aims to create a relation of reciprocity and mutual accommodation between ethics and morality. In reality, ethics has primacy and what is to be sought is not to accommodate these two ideas but to fully derive morality from ethics.

Key words: Dworkin, Equality, Morality, Ethics, Liberalism

Sumario. I. El liberalismo igualitario de Dworkin. II. Concepciones alternativas de la igualdad: La igualdad política. III. Concepciones alternativas de la igualdad: La igualdad mística. IV. Reflexiones en torno a la primacía de la ética. $V$. Conclusiones. Referencias bibliográficas

Ronald Dworkin falleció en el 2013, pero su influencia continúa creciendo. Sorprendentemente, no es en el mundo de la filosofía del derecho donde la presencia de Dworkin se hace sentir. $\mathrm{Su}$ teoría del derecho como interpretación ha tenido un impacto limitado. La escuela positivista de Hart sigue siendo la dominante en el mundo angloparlante (Leiter, 2004). En Europa el nopositivismo de Dworkin ${ }^{1}$ ha tenido más éxito de la mano de autores como Aarnio, Alexy y Peczenic. Pero si bien estos autores tomaron Los Derechos en Serio (Dworkin, 1978) como un punto de partida importante, se adentraron rápidamente en profundidades que

\footnotetext{
${ }^{1}$ Dworkin rechaza el positivismo jurídico, pero no afirma un derecho natural, por lo que no se le podría llamar iusnaturalista.
}

Ius Humani, v. 5 (2016), p. 106 
Dworkin siempre pasó por alto: el análisis del discurso, la naturaleza de la realidad social y la lógica de las normas. La influencia persistente y creciente de Dworkin se ve más bien en su liberalismo igualitario.

El presente artículo es un análisis crítico de este aspecto del legado de Dworkin, pero también va más lejos y utiliza la crítica a Dworkin como la base para explicar la importancia de la subjetividad ética en la fundamentación de teorías políticas. El artículo se divide de la siguiente manera. La primera sección es expositiva: introduce el liberalismo igualitario de Dworkin; la segunda sección y la tercera son críticas: presentan dos concepciones de la igualdad que son superiores a la igualdad liberal y que juntas dejan poco o ningún espacio para el tipo de igualdad favorecida por éste autor. La cuarta sección busca derivar conclusiones más amplias a partir de la crítica precedente. Se identifica cierto desfase entre ética y moral como la base de las falencias diagnosticadas en el pensamiento de Dworkin y como remedio se aboga por darle a la ética un rol dominante en la fundamentación de la moral. Finalmente la última sección presenta breves conclusiones.

Antes de criticar el pensamiento de alguien hay que exponerlo de una forma justa y precisa. Lo contrario es caer en la falacia informal del "muñeco de paja". Hacer esto respecto del pensamiento político de Dworkin es complicado. No sólo porque la obra de Dworkin es vasta e interconectada, y así sus teorías jurídicas informan sus teorías políticas y viceversa. También porque la metodología de Dworkin vuelve sus tesis escurridizas. Toda la obra de Dworkin se presenta como la búsqueda de coherencia entre conceptos interpretativos moralizados. Esto le permite responder a las críticas privatizando (o intentando privatizar) el lenguaje común. Si alguien le sostiene, por ejemplo, que su teoría del derecho es antidemocrática pues merma el poder de los ciudadanos de decidir cómo se organiza la sociedad y privilegia la opinión de los jueces, Dworkin puede decir que la 
democracia, bien interpretada, es fundamentalmente igual consideración y respeto, y esto naturalmente puede exigir la intervención judicial. Así las objeciones parecen quedarse sin piso, pero también parece que se ha cambiado de tema. Esta dificultad, sin embargo, no nos libera de la necesidad de resumir el igualitarismo de Dworkin de forma precisa y la sección que sigue asume esta tarea.

\section{EL LIBERALISMO IGUALITARIO DE DWORKIN}

Hablar de "liberalismo igualitario" es para Dworkin prácticamente un pleonasmo. Dworkin identifica el liberalismo con la igualdad (Dworkin, 1998). La libertad es algo secundario para Dworkin, pues es algo demasiado abstracto (Dworkin, 1998, pág. 189), algo que no tiene valor intrínseco (Dworkin, 2002, pág. 121). De haber conflicto entre igualdad y libertad siempre es la primera la que debe ceder (Dworkin 2002, págs. 128, 130). No existe un derecho general a la libertad (Dworkin, 1978, pág. 277), pero la igualdad es el derecho fundamental y omnicomprensivo que define lo que realmente es el liberalismo.

La igualdad liberal para Dworkin se resume en una fórmula que ya puede encontrarse en su famoso libro Los Derechos en Serio (1978, pág. ix). El Estado les debe a todos los ciudadanos igual consideración y respeto (equal concern and respect). Esta fórmula se repite a través del canon de Dworkin. Aparece en Una Cuestión de Principio (1985), en Virtud Soberana (2002, págs. 1, 411), en Justicia para Erizos (2011, pág. 2) y en otros lugares. La fórmula plantea un doble rol para el estado. La consideración supone una actividad positiva de apoyo y ayuda para los planes de vida de cada ciudadano; el respeto supone una actividad negativa del estado que dé espacio a cada ciudadano de desarrollar sus planes de vida de forma autónoma. Esto se concretiza en un estado de bienestar fuerte que busca asegurar la misma cantidad de recursos para todos los ciudadanos, y que erige luego una barrera a las interferencias del 
mismo estado o de terceros con los planes de vida de cada uno (1978, págs. 272-274).

Dworkin divide el campo de lo normativo en dos diferenciando la moral de la ética (Dworkin, 2011, págs. 13-15, $191)^{2}$. Esta diferenciación es esencial para el resto de este trabajo y se hará a ella de forma repetida. Para Dworkin la moral es precisamente el dominio de la igualdad (como él la concibe), y un componente esencial del derecho. La moral está constituida por normas objetivas que definen los límites de la coerción estatal permisible (Dworkin, 1986, págs. 127, 380). La ética en cambio, se refiere a los deberes que tenemos todos de hacer de nuestra vida algo de valor. La moral es pública y la ética es profundamente privada. Como veremos más adelante, Dworkin intenta empatar la ética y la moral, y sostiene que hay una relación de reenvío entre ambas, pero en realidad la estructura de su teoría las hace más independientes de lo que deberían ser.

La igualdad es el estándar aplicable por defecto para juzgar la legalidad y la legitimidad de cualquier política pública. El estado se puede apartar de la igualdad siempre y cuando tenga razones objetivas para hacerlo. Estas razones objetivas hacen referencia a lo que todos podemos aceptar desde un punto de vista moral e igualitario. En consecuencia, la igualdad en la práctica, solo puede verse desplazada por consideraciones igualitarias de naturaleza más profundas, no por consideraciones utilitarias o perfeccionistas (Dworkin, 1978, págs. 180, 274; 2002, págs. 2-3). Esto deja abierta la puerta a causar desigualdad para obtener una igualdad mucho mayor. En este sentido la igualdad es entendida por Dworkin de forma "teleológica", como un fin a lograr. El estado debe tomar todas las medidas necesarias para llegar a un estado de igualdad incluyendo medidas superficialmente desiguales. Medidas como la

\footnotetext{
${ }^{2}$ Dworkin no es el único en hacer esta diferenciación. La misma aparece, por ejemplo, en la obra de Bernard Williams (1985). La distinción entre ética y moral no siempre se hace. En el mundo filosófico angloparlante es común tratar ambos conceptos como sinónimos.
} 
acción afirmativa son acogidas positivamente por Dworkin (1985, págs. 302-303; 2002, capítulos 11 y 12; 2011, pág. 391).

El concepto de igualdad es "interpretativo" y de esta forma se encuadra dentro de la larga lista de cosas que Dworkin considera son interpretativas: el derecho, la justicia, los valores, el libre albedrio. Lo que el adjetivo "interpretativo" indica es que el significado de un concepto interpretativo se identifica con la "mejor teoría disponible" de ese concepto; aquella que presenta al concepto en su mejor luz (Dworkin, 1986, capítulo 2). La importancia que Dworkin le da a los conceptos interpretativos da lugar a dudas y objeciones.

La interpretación tiene límites implícitos. Hay cosas que no pueden interpretarse porque no son textos y hay lecturas que no son interpretaciones, pero Dworkin no desarrolla una teoría de los límites de la interpretación que constituya una fuente de restricciones seria para sus ambiciones teóricas. El admite que una interpretación debe ser coherente con otras interpretaciones, pero esto sirve de poco. Identificar cuál de dos o más teorías es la más coherente es algo bastante impracticable. Cada teórico señalará que su teoría es más coherente, sin que haya un procedimiento para elegir una sobre la otra. Un debate respecto de la coherencia de dos teorías complejas degenera rápidamente en mera insistencia y aseveraciones circulares. Así, por ejemplo, Sharon Street (2016) señala que la teoría de realismo moral de Dworkin debe ser falsa porque no es coherente con la teoría de la evolución. Thomas Nagel señala que la teoría de la evolución debe ser falsa porque no es coherente con el objetivismo moral de Dworkin (Nagel, 2012, pág. 111). Por otro lado, el valor de la coherencia es cuestionable. Una teoría muy coherente puede ser falsa, y una menos coherente verdadera.

Como la coherencia no es una verdadera restricción, para todos los efectos prácticos, cuando algo es identificado como un concepto interpretativo, se le permite a Dworkin operar libremente y moldear el concepto a su manera. Cada vez que Dworkin declara 
que un concepto es interpretativo, desaparece la posibilidad de recibir malas noticias respecto de este concepto. El libre albedrio no puede ser una ilusión, el derecho no puede ser inmoral, la religión no puede ser algo restrictivo y exigente, y al final del día los valores no pueden realmente entrar en conflicto. Esta imposibilidad de perder en el juego interpretativo merece un grado de sospecha. Hace pensar en las teorías no falsificables criticadas por Popper.

Con todo, el despliegue del concepto de igualdad que aparece en la obra de Dworkin puede parecer imponente. Si los utilitaristas ganaron mucho terreno con fórmulas como «la mayor felicidad para el mayor número» (the greatest happiness for the greatest number), cuánto más puede lograr Dworkin con un slogan (equal concern and respect) que no sólo es más corto, sino que tiene un elemento distribucional explícito. Las distribuciones importan. El principio de la utilidad aparentemente nos compele a matar a un inocente para producir ventajas para un número suficientemente grande de personas. Pensemos en los entretenimientos del circo romano ${ }^{3}$. La fórmula de Dworkin, por el contrario, no consigna a nadie a los leones, al menos no a primera vista.

Sin embargo, la concepción de la igualdad de Dworkin tiene debilidades significativas y es el propósito de este trabajo traerlas a la luz. Hacerlo nos obligará a cuestionarnos a profundidad el

\footnotetext{
3 "Aparentemente" porque en la práctica nadie sabe lo que el utilitarismo requiere. Las formas estándar de utilitarismo son un cheque en blanco a un estudio empírico que nadie ha realizado. Bentham diría que la utilidad producida por el circo romano sería derrotada por la inseguridad de ser una potencial víctima del espectáculo. Pero siendo que esta aseveración es de naturaleza empírica, nos vemos obligados a concluir que a falta de un estudio sobre los efectos de esta forma de entretenimiento realmente no sabemos si el circo terminaría con saldo en contra o a favor. Este es un rasgo objetable del utilitarismo estándar: que desplaza a la ética a un futuro tan incierto como irrelevante. También cabe la duda de si los estudios empíricos requeridos son en principio realizables. Curiosamente, a pesar de ser considerado por algunos como precursores del utilitarismo, ni Hobbes, ni Hume tienen este problema.
} 
significado y el valor de la igualdad. Casi nadie duda de la importancia de la igualdad, pero la concepción liberal de la igualdad de Dworkin no es la más sólida. Esto se puede ver más claramente a la luz de dos concepciones de la igualdad que colisionan con la concepción liberal de Dworkin. La igualdad política y la igualdad "mística". El problema para Dworkin es que si estas dos concepciones son defendibles, queda poco o nada de espacio para la igualdad liberal que él propone ${ }^{4}$.

\section{CONCEPCIONES ALTERNATIVAS DE LA IGUALDAD: LA IGUALDAD POLÍTICA}

La igualdad política es una concepción de la igualdad desarrollada en la línea de pensamiento contractual que desciende de Thomas Hobbes. En esta sección vamos a presentar el pensamiento de Hobbes puesto al día a la luz de la obra de representantes modernos del pensamiento contractual hobbesiano como David Gauthier (1986; 2005) y Bernard Gert (2010).

El eje del pensamiento contractual hobbesiano es que todos los seres humanos somos iguales en la medida en que somos igualmente vulnerables. Ciertamente hay hombres más fuertes y hombres más débiles, pero las diferencias en poder y fortaleza no son suficientes para impedir que los débiles sean un peligro para los fuertes. Siendo que a todos nos interesa reducir los riesgos en nuestra vida, evitar los costos causados por conflictos con los demás y obtener las ventajas que da la cooperación, todos tenemos un incentivo de establecer un régimen político que asegure nuestra

\footnotetext{
${ }^{4}$ Aquí no entramos en detalle respecto de la discusión que hace Dworkin sobre igualdad de bienestar versus igualdad de recursos y de su incorporación de criterios de responsabilidad en la distribución de recursos. Esto puede ser visto como una contribución valiosa dentro del igualitarismo liberal, pero nuestra crítica se enfoca en cuestionar el liberalismo igualitario como un todo.
}

Ius Humani, v. 5 (2016), p. 112 
participación voluntaria ${ }^{5}$ Y Y siendo que las diferencias arbitrarias alimentan pasiones y resentimientos que impiden la cooperación, el régimen debe tener un carácter igualitario (Gauthier, 2005). Pero esta igualdad difiere de la igualdad liberal defendida por Dworkin tanto en sus fundamentos como en sus implicaciones prácticas.

Dos diferencias fundacionales con el igualitarismo de Dworkin merecen ser resaltadas. La primera es que la igualdad hobbesiana se basa en hechos. Los hombres somos de facto relativamente iguales en nuestra capacidad de ser un riesgo los unos para los otros, el conflicto es costoso y la cooperación es beneficiosa. Esto inmediatamente le da a la teoría de Hobbes más solidez que el esfuerzo interpretativo de Dworkin. En un contexto político es de esperarse que muchos encontremos que el relleno que hace Dworkin de los conceptos interpretativos es objetable y que la teoría de Dworkin no es tan coherente como él pretende que es. Pero los hechos seguirán siendo hechos y, al no depender de las opiniones de nadie, pueden constituir un punto de referencia neutral para las partes en conflicto. La segunda diferencia consiste en que la igualdad hobbesiana es un derivado del autointerés de los ciudadanos, y no una exigencia que se impone encima de ellos. La igualdad hobbesiana busca derivar la moral de la ética (en el sentido

${ }^{5}$ El famoso pasaje de Hobbes describiendo las penurias de la vida, lejos de un orden social y político, es usualmente recortado. No sólo es la vida en conflicto corta y brutal, también desaparecen los beneficios de la cooperación y de la paz.

«Whatsoever therefore is consequent to a time of Warre, where every man is Enemy to every man; the same is consequent to the time, wherein men live without other security, than what their own strength, and their own invention shall furnish them with all. In such condition, there is no place for Industry; because the fruit thereof is uncertain; and consequently no Culture of the Earth; no Navigation, nor use of the commodities that may be imported by Sea; no commodious Building; no Instruments of moving, and removing such things as require much force; no Knowledge of the face of the Earth; no account of Time; no Arts; no Letters; no Society; and which is worst of all, continuall feare, and danger of violent death; And the life of man, solitary, poore, nasty, brutish, and short». Ver Hobbes, 1651, capítulo XIII. 
que Dworkin usa estos términos) sin dejar residuo (Gauthier, 1986, págs. 6-8).

Estas dos diferencias fundacionales llevan a conclusiones muy distintas respecto de que tipo de orden social es exigido por la igualdad. Consideremos algunos puntos:

La igualdad liberal defendida por Dworkin se define de forma independiente de las aspiraciones éticas de los ciudadanos a través de un esfuerzo intelectual de rellenar conceptos interpretativos de una forma convincente y coherente. La igualdad para Dworkin es en cierto sentido una construcción intelectual ${ }^{6}$. Definir la moral, la igualdad, etc. exige un esfuerzo filosófico y esto les da a los jueces y a los intelectuales un rol central en determinar qué es lo justo. Consiguientemente, el esquema de Dworkin ampara un gobierno judicial de estilo "neoconstitucional" que articule lo que la moral exige (Dworkin, 1985, págs. 66-68; 1993, pág. 123; 1996; 2002 capítulo 4). La igualdad para Hobbes es un hecho, que en circunstancias normales se va a manifestar en la constitución del orden social. Los jueces y los intelectuales no tienen que crear o definir esta igualdad que existe de facto, y tampoco tienen un rol determinante que jugar en definir el contenido del orden social pues ellos no pueden representar los intereses dispares de los ciudadanos. Lo que sí se espera es que los jueces respeten el orden social constituido. Consiguientemente la igualdad hobbesiana exige jueces fieles al orden social que protejan las expectativas que este orden crea.

Dworkin legitima el uso de medidas desiguales como la acción afirmativa y la intervención activista de los jueces constitucionales como medios para obtener más igualdad que es el fin último de la organización social. El pensamiento hobbesiano mira este tipo de medidas con mucho escepticismo, pues su teoría no permite el sacrificio del orden social para obtener "beneficios

\footnotetext{
${ }^{6}$ Dworkin insiste que los valores morales son objetivos (1996), pero parecería que esta palabra es sencillamente es un blasón que Dworkin añade después de haber terminado una investigación esencialmente constructivista.
}

Ius Humani, v. 5 (2016), p. 114 
mayores". En el esquema de Hobbes no existe un fin común que una a los ciudadanos, su única unión es la unión política que establece un régimen de cooperación. Romper este régimen está prohibido, ya sea porque se desea obtener beneficios egoístas más allá de lo que el régimen permite, o porque se desea imponer un sistema mejor de forma altruista o igualitaria. Desde la perspectiva hobbesiana los buenos deseos de los activistas igualitarios siempre serán sus buenos deseos, que por más que sean percibidos como justos desde su perspectiva, serán injustos para otros. Ponerlos por encima del orden constituido es invitar reacciones y represalias.

Las prácticas no convencionales o impopulares tienen un estatus diferente en los sistemas de Dworkin y de Hobbes. Para Dworkin son prácticamente sagradas. Dworkin objeta al harm principle de Mill pues considera que éste le da una protección demasiado débil a las prácticas impopulares (Dworkin, 1985, capítulo 17). Para este autor una de las principales tareas de los jueces es precisamente crear islas para la protección de los diferentes estilos de vida de los ciudadanos, cualquiera que estos sean. En el esquema de Hobbes se podría decir que si bien cada ciudadano tiene un interés en defender sus planes de vida, él está obligado a persuadir a los otros de que los beneficios de cooperar con él son superiores a los beneficios de excluirlo de la organización social. Como se ha señalado, el orden social es construido a partir del autointerés de todos los ciudadanos, por lo tanto, no existe una medida pre-política o supra-política que sirva para definir (ciertas) prácticas impopulares como innegociables.

Nos hemos acostumbrado tanto a la línea de pensamiento neo-kantiana (a la que Dworkin pertenece) que nos parece natural que la igualdad implique la protección de un amplio espacio privado blindado frente a la intervención pública. Sin embargo, asegurar una esfera privada amplia y darles preferencias a las minorías no es algo indiscutiblemente neutral o igualitario. Esto privilegia una concepción particular del significado de lo público y de lo privado por encima de concepciones alternativas. Ciertamente 
hay que trazar una línea divisoria y hay que distribuir derechos entre mayorías y minorías, pero al final del día Dworkin no tiene una justificación que no sea circular de por qué habría que preferirse una distribución sobre otra. Hobbes, al dejar el tema abierto al proceso político, no tiene este problema.

Es importante recalcar que la igualdad de Dworkin no es una igualdad política aunque a veces la presente retóricamente como tal (Dworkin, 2002, capítulo 4). Todo lo que es propiamente político - el conflicto de intereses, el juego de poder - ha sido censurado de antemano. Esto lo vemos sobre todo, en su afán de redefinir moralmente la democracia para ajustarla a los cánones de lo que él considera aceptable (algo muy visible en Dworkin, 1999 y 2002, capítulo 4). El problema de Dworkin aquí es uno que comparte con sus colegas de inspiración neo-kantiana y una variedad de "demócratas deliberativos". La política democrática se apoya siempre y cuando sea liberal, tolerante, respetuosa de los derechos, igualitaria etc..., pero es filósofo, no el proceso político, el que define el significado del liberalismo, de la tolerancia y de la igualdad. Entonces el filósofo liberal e igualitario termina asumiendo una posición abusiva. Cuando su voto y su voz en la calle no le bastan, busca el veto judicial con el pretexto de que esto protege los derechos y la justicia que sostiene son las precondiciones de la democracia. Pero al calificar a algo como precondición lo substrae del sistema político, lo vuelve algo que él puede definir de forma unilateral a la luz de criterios vacuos como la coherencia y los conceptos interpretativos.

Dworkin le da muy poco crédito al esquema contractual hobbesiano. El apela a la importancia de mantener sagrados los principios y los derechos, de no intercambiarlos por otras consideraciones que en algún momento se pueden percibir como más importantes (Dworkin, 2002, pág. 137). Refiriéndose a la posibilidad de que aspectos impopulares de los derechos sean sacrificados por un proceso político hobbesiano, Dworkin argumenta lo siguiente: 
«Si bien los contractualistas podrían decir que si las personas reflexionasen de forma calmada en un problema, viendo los buenos argumentos que existen, no aceptarían intercambiar libertades por ninguna otra cosa. Pero esto es silbar en la oscuridad, un acto de fe; ipor qué sería irracional para alguien que sabe que sus convicciones políticas son convencionales intercambiar la libertad de hacer demostraciones políticas por cualquier otra ventaja?» ${ }^{7}$.

Para ojos hobbesianos, esto es prácticamente una cándida confesión de parte de Dworkin de que él se considera el justo censor de las opiniones políticas de aquellos que él cree, son menos iluminados y menos valientes que él. ¿Qué tiene de malo que una sociedad sacrifique libertades no convencionales para obtener otros beneficios? ¿Por qué es evidentemente objetable y fuera de discusión que una sociedad limite el derecho a consumir pornografía o a quemar una bandera (ejemplos frecuentes de Dworkin) en búsqueda de la virtud cívica? ¿Evidente para quién? Es fácil entender que a Dworkin no le guste que se sacrifiquen ciertos principios, a mí no me gusta que se sacrifiquen otros principios, diferentes a los que Dworkin prefiere, pero que ciertos principios nos gusten mucho no los pone en un pedestal. El verdadero acuerdo social hobbesiano sí tiene un pedestal: es el acuerdo que asegura la cooperación, sin la cual la vida en sociedad sería imposible, sin la cual estaríamos condenados a las penurias de la vida solitaria y el conflicto permanente.

Antes de concluir esta sección, vale la pena reflexionar acerca del poder justificativo de las teorías aquí en discusión. Dworkin tiene que persuadirnos de que respetemos el orden social porque éste refleja igual consideración y respeto, o el mejor equilibrio

«Contractarians... might claim that if people reflected on the issue calmly, with good arguments before them, they would in fact decline to trade part of their liberty for anything else. But that seems just another whistling-in-the-dark act of faith... why is it irrational for someone who knows that his own political convictions are conventional to trade off the general liberty of political demonstration for whatever advantages he believe this would bring him?», Dworkin, 2002, págs. 137-138). 
existente de valores, o una interpretación armoniosa de nuestra vida comunal, o algo por el estilo. Hobbes sencillamente tiene que mostrar que sin el orden social estaríamos individualmente, mucho peor de lo que estamos ahora. En la medida que los problemas éticos no son problemas meramente intelectuales, sino problemas volitivos y apetitivos, está claro que la justificación que ofrece Dworkin no llega al corazón del asunto, mientras que la que ofrece Hobbes sí.

\section{CONCEPCIONES ALTERNATIVAS DE LA IGUALDAD: LA IGUALDAD MÍSTICA}

En oposición a la igualdad liberal de Dworkin podemos hablar también de una igualdad "mística" (este calificativo es tomado de la obra de Elizabeth Anscombe, quien lo usa para referirse a valores no instrumentales que no siempre son percibidos por todos). Cada ser humano es igualmente humano y esto implica una exigencia de respeto y reverencia. "Ser humano" aquí es un "concepto espeso" (Williams, 1985, págs. 140-141) cuyo uso involucra una mezcla indisoluble de elementos cognitivos y volitivos. Reconocer a alguien como ser humano no es meramente entenderlo como parte de la especie homo sapiens. Este reconocimiento nos llama a adoptar una actitud de comunidad, de solidaridad, frente a él a la luz de lo compartido por todos los hombres. Pensemos aquí en la famosa frase de Publio Terencio Africano homo sum, humani nihil a me alienum puto. Ciertamente, con decir esto, Terencio no pretende informarnos de que él es un homo sapiens y no otra cosa, por ejemplo, un neandertal. Tampoco estamos frente a una mera arenga disfrazada de aseveración como "los niños buenos obedecen a sus padres" que podría expresarse mejor como "iobedece a tus padres!”. Esta frase comunica un hecho 
cuya comprensión intelectual está atada a cierta comprensión práctica salvando la brecha entre el ser y el deber $\operatorname{ser}^{8}$.

A pesar de la existencia de pasajes altisonantes y poéticos en su obra, a pesar de usar un lenguaje que es apropiado para hablar de la igualdad mística, la igualdad de Dworkin no es de esta naturaleza. La igualdad mística exige cosas por encima y por debajo de lo que la fórmula de Dworkin contempla.

Por un lado, la igualdad mística nos llama a irrespetar la autonomía individual para asegurar que las personas se mantengan dentro de los márgenes de la dignidad. Alguien que está comprometido con la igualdad mística no puede sencillamente abandonar a otras personas al plan de vida que han elegido, si este involucra, por ejemplo, asegurarse de que otros le quiten vida en caso de convertirse en ancianos con Alzheimer (Dworkin sostiene que puede ser necesario matar a ancianos con Alzheimer que no quieren morir, y que llevan una vida inocente y feliz, si la persona en cuestión testó esta exigencia antes de tener Alzheimer. Ver Dworkin, 1993, págs. 228-233), ni se sentirá cómodo en un estado que exija que algo así se respete. El trabajo de D.A.J. Richards que defiende el derecho humano a drogarse usando premisas igualitarias es otro ejemplo de la tendencia criticada. Decir que da igual dedicarse al deporte o la heroína, y que ambas actividades merecen igual consideración y respeto es igualitario en un sentido artificial y bastante forzado. Este "respeto" niega la igual humanidad, la fraternidad que informa concepciones más profundas de la igualdad que nos llevarían a tratar de impedir que

\footnotetext{
${ }^{8}$ La idea de que existe una brecha entre ser y deber ser se atribuye a David Hume, pero en realidad, Hume se refería a la imposibilidad de derivar conclusiones morales sin la mediación de inputs emocionales, y las emociones son ciertamente parte del "ser". Hume es sin lugar a duda parte de la tradición naturalista que incluye a Aristóteles y Tomás de Aquino. ¿De qué otra forma podemos entender el rol que él le da, en su Tratado Sobre la Naturaleza Humana, a una descripción antropológica como base para la aprehensión subjetiva del valor ético de una norma o costumbre? Vid. Hume, 1740, libro III, parte III, sección VI. La presente sección y la siguiente se inspiran en gran medida en el pensamiento de Hume.
} 
una persona utilice heroína u otra droga similar (vid. Richards, 1986, pág. 176 et passim. Richards invoca a Dworkin y su fórmula de igual consideración y respeto).

Por otro lado, la igualdad mística no tiene que preocuparse por desigualdades en ingresos, en la facilidad o dificultad de la satisfacción de planes de vida, y demás diferencias superficiales entre los seres humanos. Mientras la igual dignidad de todos se mantenga incólume, estas diferencias son tolerables y aptas para la discusión política. Quizá este tipo de consideraciones están detrás de la petición de San Pablo «esclavos, obedezcan en todo a sus dueños temporales, pero no con una obediencia fingida, como quien trata de agradar a los hombres, sino con sencillez de corazón, por consideración al Señor» (Colosenses 3, 22). Ciertamente la esclavitud es profundamente repugnante y absolutamente injustificable, pero no es imposible que exista una forma de vivir dentro de un régimen absolutamente desigual en el sentido político que respete la dignidad mística (claro está, hay formas de esclavitud que sí violentan la igualdad mística de forma inmediata, como la llamada chattel slavery que se dio en Estados Unidos y en otros lugares).

Las diferencias entre la igualdad liberal que Dworkin propone y la igualdad mística, y diferentes interpretaciones de la idea de la dignidad salen a la luz en la intervención de Dworkin en el debate sobre el aborto y la eutanasia (discutidos en Dworkin, 1993). Dworkin puede entender que en ambos casos, hay muchos para quienes nos parece que no es ético abortar o practicar la eutanasia. Pero para Dworkin, en ambos casos, la moral exige que entendamos que esto es nuestra convicción personal, que tiene que ser subordinada a la autonomía de cada uno de dirigir su vida como desea. Sin embargo, en la medida que la oposición al aborto se fundamenta en un concepto espeso como el desarrollado en el principio de esta sección, la propuesta de Dworkin no tiene sentido. El concepto espeso de "ser humano inocente" exige un compromiso volitivo de protección y amparo, que es totalmente incompatible 
con la actitud desapegada, escéptica y deferente que plantea Dworkin. Admitir esta actitud de desapego sería precisamente perder el concepto.

Naturalmente, no todos van a compartir la concepción de ser humano que se plantea al inicio de esta sección, y no todos estarán de acuerdo en sus implicaciones. Esto da lugar a ciertas dudas y ansiedades. ¿Por qué habría de privilegiarse la opinión de algunos sobre el aborto o la eutanasia sobre la de otros? ¿Cómo puede ser esto más equitativo que darle a cada uno igual posibilidad de desarrollar su vida? ¿Acaso no es profundamente discriminatorio imponerles a otros cómo vivir? Estas dudas merecen la siguiente réplica.

Primero, hay que darnos cuenta de lo mucho que estas preguntas constituyen una petición de principio. Dado su enfoque epistémico — no sabemos cuál es la verdad, entonces le damos a todos igual oportunidad de llegar a una respuesta - estas preguntas privilegian una concepción del ser humano como razonador y libre decisor. Si éste es nuestro punto de partida es natural esperar que la igualdad se base en una forma de deferencia epistémica agnóstica (Reiman hace esta conexión de forma explícita, y sí se muestra bastante abierto a matar seres humanos no plenamente racionales. Vid. Reiman, 1997, capítulos 6 y 13). Sin embargo, no hay razón para pensar que la igualdad debe manifestarse primero y antes que nada en lo epistémico. La igualdad mística privilegia una concepción diferente del ser humano. Concibe a todo ser humano como a un pariente de la familia humana, como alguien a ser protegido y amparado, incluso de sus propias ideas y decisiones. En la medida que ambas teorías tienen una idea implícita o explícita de que es lo esencial en el ser humano, no es evidente porque hay que comenzar por el pensamiento y la libertad y no por la vulnerabilidad y la mutua dependencia.

Segundo, que una convicción sea no-compartida no implica que haga sentido subordinarla a una que sí lo es. Al contrario, hay convicciones que sencillamente no podemos subordinar aunque no 
sean compartidas por todos. Esto sucede con las convicciones que tienen un rol fundamental en la construcción de nuestra vida individual y colectiva (ver Wittgenstein, 1969, §§ 341-344; Williams, 1985, págs. 113-115).

Raymond Gaita (Gaita, 2000, pág. 177) nos da un ejemplo que servirá para poner nuestras convicciones en alto relieve:

«En los principios de los noventa un hombre en Londres, cuchillo en mano, exigió dinero a una joven madre que empujaba a su bebé en un coche. El amenazó a la madre con mutilar al bebe si se negaba. Ella le dio su cartera y sus joyas. El luego cortó al bebé en la cara y en el cuerpo. El bebé murió en el hospital. La madre fue admitida a un hospital psiquiátrico» ${ }^{9}$.

La maldad de este acto es una convicción fundamental. No necesitamos una teoría que nos diga que este acto es perverso. Esto no es una mera intuición, que una teoría tiene que explicar o justificar. Cualquier teoría explicativa o justificativa que podamos desarrollar será menos confiable que nuestra percepción de que el acto descrito es prohibido. En este sentido podría decirse que, en este caso, el ejemplo se impone por encima de la teoría, invirtiendo el orden normal de las explicaciones y justificaciones.

Imaginemos que aparece un filósofo que argumenta que el asesino en cuestión merece una pena muy descontada porque el bebé asesinado no era aún una persona pues no tneía plena consciencia de sí (Tooley, 1983; vid. también Singer, 2011, pág. 152). Para este filósofo el hecho de que la madre esté enferma por lo sucedido es un daño que también merece ser descontado, pues es un daño causado por creencias injustificables de la madre (Thomson, 1992, pág. 250). El filósofo dirá que esta mujer no puede ofrecerle al filósofo un atributo presente en el bebé que lo

9

«In the early nineties a man in London, brandishing a knife demanded money of a young mother who was wheeling her baby. He threatened to mutilate the baby if she refused. She gave him her purse and her jewelry. He then slashed the baby's face and body and ran off. The baby died in hospital. The mother was admitted to a psychiatric hospital».

Ius Humani, v. 5 (2016), p. 122 
diferencie de otros animales que no son personas, cuya muerte ella acepta sin mayor problema. Si la madre sufre de algo es de "especismo": una preferencia arbitraria por los miembros de su propia especie ${ }^{10}$ (como se puede ver de las referencias insertas en el texto, este personaje filosófico es bastante real).

No necesitamos refutar estas teorías dialécticamente para sostener que son falsas. Si se nos exige más explicación no hace falta más que insistir en la descripción que acabamos de presentar. En la crueldad de cortar a un bebe de forma tan gratuita en la presencia de su madre. Si nuestro interlocutor no considera que eso no es una razón y prefiere proseguir con una dialéctica exigiendo "razones" (término cuyo significado comienza a parecer muy oscuro $^{11}$ ), no tenemos ninguna obligación de continuar el ejercicio, ni tampoco motivos para volvernos agnósticos respecto de la valencia moral de lo sucedido y buscar un procedimiento neutral para salvar la cuestión como un cálculo utilitarista o un debate bajo las exigencias de la razón pública. Esto a pesar de que no tenemos argumentos compartidos que puedan justificar nuestra creencia,

${ }^{10}$ La ridícula acusación de "especismo" se ha vuelto tan común que su aparición en este ensayo merece algún comentario. Esta acusación parece no comprender que existen obligaciones de pertenencia. Así por ejemplo Margaret Olivia Little sostiene que para la visión moral de la Ilustración, la pertenencia a un grupo nunca es un buen fundamento para derivar conclusiones morales (Little, 2007, pág. 336). Ciertamente esto es falso, a menos que queramos quitar a Hume, a Smith y a Marx de la lista de los ilustrados. Y si fuera verdadero, esto sería catastrófico para la Ilustración. Una civilización sin conceptos de pertenencia y tradición está condenada a desaparecer. La idea de que tengamos obligaciones de pertenencia generalizadas, a la especie humana como un todo, no es algo de que avergonzarse, sino todo lo contrario una idea frágil que hay que atesorar. En relación a esto ver Williams 2006, capítulo 13, The human prejudice.

${ }^{11}$ Singer es proclive a exigir que se dé una razón para preferir un animal por encima un ser humano de capacidades similares. Al hacer esto está pasa por alto la razón evidente que salta a la vista: es un ser humano; es un niño, es un bebé, etc. Si eso para Singer no constituye una razón, debemos pensar que él tiene una teoría bastante extraña de lo que son las razones que ciertamente no tenemos que aceptar como parte de un ejercicio dialéctico. 
argumentos que puedan ser inmediatamente aceptados por todos. La fuerza de nuestra convicción es cualitativamente mayor a la convicción que podemos tener respecto de la validez de procedimientos neutrales de justificación moral. Podríamos decir, ¿si el asesinato de un bebe es algo respecto de lo que debo cultivar agnosticismo e indiferencia, entonces por qué habría de importarme el liberalismo, la moral y la justicia?

Esto no quiere decir que no podamos estar equivocados respecto de las convicciones que se nos presentan como indiscutibles e irrechazables. Esto es enteramente posible. Pero para demostrar el error de una convicción de esta naturaleza no basta presentar argumentos en contra de ella. Es necesario lograr que la persona que la percibe deje de percibirla. De otra forma, no podemos razonablemente negar aquello que tiene la fuerza de una convicción natural sin socavar las bases mismas de nuestra actividad práctica y cognoscitiva en el mundo. Sin anclas en convicciones fundamentales, cuestiones más complejas pierden sentido.

Naturalmente, no todos tenemos la misma percepción acerca de la igualdad mística. Esto no es una cuestión de culturas, pues como vimos en el ejemplo, muchos filósofos angloamericanos como Singer, Tooley y Thomson no tienen, o pretenden no tener, esta idea del ser humano, mientras otros como Gaita la defienden. Aun otros como Cora Diamond (1978) sí tienen esta convicción, pero la hacen extensiva a los animales (no sin reservas). La inevitable disparidad de convicciones respecto de la igualdad mística no nos puede obligar a abandonarla, sólo nos sugiere que esta igualdad no puede cumplir un rol político de dirimir conflictos. Ciertamente necesitamos un orden social que acapare a las visiones de personas dispares, pero esto nos remite de vuelta a la igualdad hobbesiana. Nada de esto nos remite obligatoriamente a la igualdad liberal de Dworkin. 


\section{REFLEXIONES EN TORNO A LA PRIMACÍA DE LA ÉTICA}

Las concepciones anteriormente usadas para criticar la igualdad liberal de Dworkin tienen algo en común. Ambas concepciones alternativas de la igualdad privilegian la convicción ética subjetiva, sobre construcciones y postulados morales que pretenden ser objetivos. En el esquema hobbesiano la ética (el interés individual) es el fundamento único de la moral compartida. Desde la perspectiva de la igualdad mística, una convicción ética no-compartida (lo místico o sagrado) puede y debe romper los esquemas de la moral putativamente neutral en caso de conflicto. En esta sección vamos más allá de la crítica a Dworkin y recalcamos la necesidad de toda teoría de conservar este rol privilegiado para la ética.

Para Dworkin la ética consiste en el arte de vivir bien y esto es algo que tiene que coincidir con la moral, pero la moral como concepto interpretativo se puede definir por cuerdas separadas. Se busca un mutuo reenvío entre moral y ética, pero no se puede identificar, sin más, moral y ética. Aquí la retórica de Dworkin es apta para confundir. El hace parecer que la conexión tenue que él construye entre moral y ética es algo singularmente fuerte. Hasta el utilitarismo brutal de Peter Singer busca este tipo de reenvíos y deja espacio para la autosatisfacción ética (1995, págs. 222-226, 260267). La distancia que existe entre moral y ética en Dworkin lo alinea con figuras modernas y dispares como Bentham y Kant, y lo pone en oposición a una tradición clásica que no busca armonizar o acomodar moral y ética, sino derivar la primera de la segunda. Esto se puede ver en autores de inspiración clásica radicalmente opuestos en sus convicciones sustantivas como Anscombe (1958) y Williams (1985). Para esta tradición hablar de una moral independiente de nuestras convicciones éticas es imposible e indeseable.

Imposible porque, nuestras posturas éticas inevitablemente dejan su huella en nuestras propuestas morales, invalidando sus 
pretensiones de neutralidad. Cuando Dworkin sostiene que la igualdad liberal es la mejor teoría política, expresa su apetencia por el liberalismo americano de Nueva Inglaterra. Cuando Bentham expresa su preferencia por el principio de la utilidad, él expresa su apetencia por un mundo hedonista y pragmático. Cuando Kant expresa su preferencia por una deontología rígida, él expresa su apetencia por un mundo ordenado y rígido. No se puede encapsular lo ético e imaginar un sistema moral neutral, correcto o apropiado de forma directa. El sistema "moral" generado en esta forma no será más que la imposición artificial de la apetencia ética de aquel quien lo diseñó más un añadido de autoridad fantasmal que viene de consigo con uso de palabras como "moral", "neutral", "igualitario" y similares. El sistema moral propuesto tendrá los vicios, las insensibilidades y sesgos de quien lo creó.

Indeseable porque un sistema moral creado con independencia de nuestros conceptos éticos tenderá a falsificar la realidad vivida de lo ético de una forma inaceptable. El que maneja conceptos morales abstractos puede fácilmente crear reglas plausibles como "el consentimiento es importante", "la violencia es mala" o "hay que buscar maximizar la felicidad", pero sin guías éticas, sin un conocimiento personal de que es lo que significa un tal acto u omisión, estas reglas van a ser utilizadas de una forma torpe, ridícula, o malintencionada. Esto se puede ver en académicos que armados de principios como los señalados no pueden ver - $\mathrm{O}$ dicen que no pueden ver- la diferencia entre la circuncisión judía y la ablación del clítoris en la mujer. $\mathrm{O}$ en académicos que pretenden que no pueden comprender la diferencia entre matar a un orangután y matar a un niño con discapacidades severas.

Indeseable también porque la ausencia de fundamentación ética crea un vacío inmenso a nivel de la motivación. La ética tiene una respuesta no siempre satisfactoria pero perfectible a la pregunta de por qué debo yo ser ético. La respuesta es siempre porque la ética define nuestro bien. En cambio la "neutralidad", la igualdad y otros conceptos puramente morales no tienen una respuesta adecuada a 
la pregunta de por qué uno debe obedecer a las normas. Esta es una receta para la inestabilidad social y quizás para el colapso. En este contexto la técnica de reenvío que usa Dworkin sólo puede tener una efectividad limitada. Cuando hay buen tiempo realmente coincidirá que la moral de Dworkin no nos exigirá mucho y nos permitirá tener un estilo de vida que nos satisfaga. Pero esto solo será posible mientras exista relativa abundancia, o mientras nuestros deseos e intereses se mantengan dentro de ciertos parámetros. Cuando estas condiciones no se dan, los verdaderos conflictos aparecen y Dworkin no tiene nada con que defender su teoría. Este punto puede levantar objeciones de egoísmo. Esto sería un error. Partir de la ética sí nos exige que las normas nos beneficien, pero este beneficio no tiene que ser autorreferencial. Dentro del bien ético se pueden incluir sin problema los sacrificios más costosos por los seres que amamos o por las causas que valoramos. Lo que no se puede admitir es un sacrificio automático, y sin más, por conceptos de igualdad o utilidad legislados por académicos.

La moral, como construcción intelectual, busca esquivar las preguntas éticas y decirnos, de forma general y abstracta, que reglas deben guiar nuestro comportamiento. Desde el punto de vista de la tradición clásica este es un proyecto destinado al fracaso.

\section{CONCLUSIONES}

El presente artículo ataca a Dworkin en dos flancos, con dos concepciones de igualdad que resultan más fuertes que la igualdad liberal que el propone. La igualdad política es más fuerte porque se basa en hechos reales e implica consecuencias para el autointerés de cada uno. La igualdad mística es más fuerte porque está anclada en nuestra comprensión del mundo. Juntas estas dos concepciones alternativas de la igualdad le dejan poco o ningún espacio a la igualdad liberal defendida por Dworkin. La igualdad política exige que los problemas políticos se resuelvan en la libre negociación de 
los ciudadanos, sin intervención de censores judiciales. La igualdad mística no acepta residir dentro de los cánones de la igualdad política. Autoriza que se rompan sus esquemas para defender percepciones relativamente incomunicables de lo justo y de lo correcto.

En contraste con la igualdad política y la igualdad mística, la igualdad de Dworkin puede llamarse igualdad ideológica. Esto quiere decir que no tiene mayor fundamento que el hecho de que es atractiva para ciertas personas, que les parece el justo equilibrio entre una gama de valores. Pero eso es todo. La igualdad de Dworkin no tiene raíz. Como concepto interpretativo, su única defensa es que realmente nos parezca la mejor forma de rellenar un concepto abstracto.

Esta crítica es generalizable a todas las teorías que pueden llamarse propiamente "morales". Es decir, teorías que definen lo correcto de forma externa a las aspiraciones subjetivas de los individuos. Aquí encontramos fácilmente a la gran mayoría de las teorías utilitarias y kantianas. En la medida que esta crítica es exitosa nos invita a abandonar tanto a Bentham como a Kant, y a mirar al pasado para encontrar mejores guías de cómo organizar a una sociedad. Nos invita mirar a la tradición de las virtudes y a sus mejores exponentes: Aristóteles, Tomás de Aquino, Hobbes, Hume y Smith. 


\section{REFERENCIAS BIBLIOGRÁFICAS}

Anscombe, G. E. (1958). Modern moral philosophy. Philosophy, 33, 124, págs. 1-19.

Diamond, C. (1978). Eating meat and eating people. Philosophy, 53, 206, págs. 465-479.

Dworkin, R. (1978). Taking rights seriously. Cambridge: Harvard University Press.

Dworkin, R. (1986). Law's Empire. Cambridge: Harvard University Press.

Dworkin, R. (1996). Objectivity and truth: You'd better believe it. Philosophy \& Public Affairs, 25, 2, págs. 87-139.

Dworkin, R. (1999). Freedom's law: the moral reading of the American Constitution. Oxford: Oxford University Press.

Dworkin, R. (2011). Justice for hedgehogs. Cambridge: Harvard University Press.

Dworkin, R. (2013). Religion without god. Cambridge: Harvard University Press.

Dworkin, Ronald, Liberalism. En Nida-Rümelin, J., \& Vossenkuhl, W. (Eds.). (1998). Ethische und politische Freiheit (págs. 180-204). Berlin: de Gruyter.

Dworkin, Ronald. (1985). A matter of principle. Oxford: Oxford University Press.

Dworkin, Ronald. Sovereign virtue: the theory and practice of equality. Cambridge: Harvard University Press, 2002.

Gaita, R. (2000). A common humanity: Thinking about love and truth and justice. London: Routledge.

Gauthier, D. P. (1986). Morals by agreement. Oxford: Oxford University Press.

Gauthier, D. P. (2005). Thomas Hobbes and the Contractarian Theory of Law. En Finkelstein, C. (Ed). Hobbes on law (págs 159-185). Aldershot, Ashgate, 2005. 
Gert, B. (2010). Hobbes. Prince of peace. Cambridge: Polity.

Hobbes, T. (1651). Leviathan, or, The matter, forme, \& power of a common-wealth ecclesiasticall and civill, varias ediciones.

Hume, D. (1740). A Treatise of Human Nature: Being an Attempt to Introduce the Experimental Method of Reasoning into Moral Subjects, varias ediciones.

Leiter, B. (2004). End of Empire: Dworkin and Jurisprudence in the 21st Century, The Rutgers Law Journal, 36, 165, págs. 165-182.

Little, M. O. (2007). Abortion and the Margins of Personhood. Rutgers Law Journal, 39, págs. 331-348.

Nagel, T. (2012). Mind and cosmos: why the materialist neo-Darwinian conception of nature is almost certainly false. Oxford: Oxford University Press.

Reiman, J. H. (1997). Critical moral liberalism: theory and practice. Lanham: Rowman \& Littlefield.

Richards, D. A. J. (1982). Sex, drugs, death and the law: An essay on human rights and overcriminalization. Totowa: Rowman and Littlefield.

Setiya, K. (2012). Knowing right from wrong. Oxford: Oxford University Press.

Singer, P. (1995). How are We to Live?: Ethics in an Age of Self-interest. Amherst: Prometheus Books.

Singer, P. (2011). Practical Ethics (tercera edición). Cambridge: Cambridge University Press.

Street, S. (2016). Objectivity and truth: You'd better rethink it. Manuscrito disponible en https://www.academia.edu/ 19887912/Objectivity_and_Truth_Youd_Better_Rethink_It (consultado el 12-V-2016).

Thomson, J. J. (1992). The realm of rights. Cambridge: Harvard University Press. 
Tooley, M. (1972). Abortion and infanticide. Philosophy \& Public Affairs, 2, 1, págs. 37-65.

Williams, B. (1985). Ethics and the Limits of Philosophy. London: Fontana.

Williams, B. (2006) Philosophy as a humanistic discipline. Princeton: Princeton University Press.

Wittgenstein L. (1969) On Certainty (Uber Gewissheit). Oxford: Basil Blackwell. 